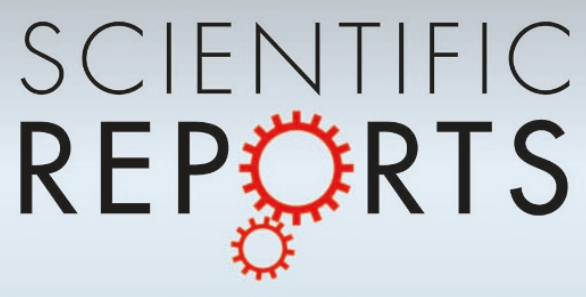

OPEN

SUBJECT AREAS:

SELF-ASSEMBLY

ORGANIC-INORGANIC NANOSTRUCTURES

TWO-DIMENSIONAL MATERIALS

SOLID-STATE CHEMISTRY

Received

24 May 2013

Accepted

20 November 2013

Published

16 December 2013

Correspondence and requests for materials should be addressed to

S.V. (svipc@ipc.iisc. ernet.in)

\title{
Engineering New Layered Solids from Exfoliated Inorganics: a Periodically Alternating Hydrotalcite - Montmorillonite Layered Hybrid
}

\author{
Rajesh Chalasani, Amit Gupta \& Sukumaran Vasudevan
}

Department of Inorganic and Physical Chemistry, Indian Institute of Science, Bangalore 560012. India.

Two-dimensional (2D) nanosheets obtained by exfoliating inorganic layered crystals have emerged as a new class of materials with unique attributes. One of the critical challenges is to develop robust and versatile methods for creating new nanostructures from these 2D-nanosheets. Here we report the delamination of layered materials that belonging to two different classes - the cationic clay, montmorillonite, and the anionic clay, hydrotalcite - by intercalation of appropriate ionic surfactants followed by dispersion in a non-polar solvent. The solids are delaminated to single layers of atomic thickness with the ionic surfactants remaining tethered to the inorganic and consequently the nanosheets are electrically neutral. We then show that when dispersions of the two solids are mixed the exfoliated sheets self-assemble as a new layered solid with periodically alternating hydrotalcite and montmorillonite layers. The procedure outlined here is easily extended to other layered solids for creating new superstructures from 2D-nanosheets by self-assembly.

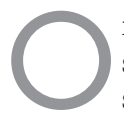

ne of the main challenges in the design of materials is the self-directed assembly of ordered superstructures from basic structural motifs. In the organic solid state and, to a lesser extent, in framework solids the concept of crystal engineering using synthetic building blocks has emerged as a successful concept for rational design ${ }^{1}$. In most other crystalline solids the ability to de-construct a solid into basic structural blocks and re-construct new solids from them is yet to be realized. These ideas are most likely to succeed in the case of layered solids where deconstruction, in this case exfoliation or delamination, procedures are reasonably well established ${ }^{2-6}$. Here we report the delamination of layered materials that belonging to two different classes the cationic clay, montmorillonite, and the anionic clay, hydrotalcite - to their ultimate constituent, intact, nanometer thick, single layers. We then show that these exfoliated sheets can be made to self-assemble as a new solid with periodically alternating hydrotalcite and montmorillonite layers.

Delamination of inorganic layered solids by exfoliation resulting in the formation of highly dispersed monolayer colloidal phases has attracted considerable interest, particularly as building blocks for the construction of functional nano-composites and nanostructures ${ }^{7-11}$. The spontaneous swelling and exfoliation of smectite clays in water to give stable colloidal dispersions is well documented ${ }^{4,12}$. Delamination has been artificially realized for a variety of different layered materials, layered oxides ${ }^{10,13-16}$, di-chalcogenides ${ }^{2,17-19}$, and metal phosphate ${ }^{20,21}$, the anionic clays or layered double hydroxides ${ }^{5,22,23}$, metal-organic framework solids ${ }^{24}$ and more recently carbides and carbonitrides ${ }^{25}$, by controlling interlayer interactions. The term 'nanosheets' has been widely used to classify these nanometer thick inorganic sheets whose lateral dimensions can extend to microns. Most reported methods have achieved exfoliation by use of highly polar solvents. The solvent molecules replace the solvation shell of the interlamellar counter ions resulting in the dilation of the layers and subsequent modification of interlayer interactions ${ }^{4}$. These methods result in the formation of either positively or negatively charged nanosheets with solvent polarity playing a crucial role in ensuring that the inorganic macro-ions remain as stable dispersions. On solvent evaporation the original solid can be recovered. There have been attempts to create new layered hybrids from a combination of dispersions of two different layered materials. Most approaches have used the "layer-bylayer" method, a thin-film fabrication technique that uses sequential adsorption of oppositely charged species on a suitable substrate ${ }^{26-30}$. New functional nanoarchitectures formed by the electrostatic layer-by-layer assembly either of negatively charged montmorillonite layers and polycations or positively charged layered double hydroxide nanosheets in combination with polyanionic counterparts (polymer, DNA, metal oxide, metal dichalcogenide 
nanosheets, etc.) have been reported ${ }^{11,31-33}$. The spontaneous flocculation of positively charged layered double hydroxide nanosheets with the complimentary, negatively charged oxide or metal dichalcogenide layers have been reported. By judicious choice of the individual components, charge balanced ordered nanostructures were obtained $^{11,28}$. What is clearly desirable is a procedure that allows for the spontaneous self-assembly of new ordered layered structures from combinations of dispersions of exfoliated inorganic nanosheets.

The layered materials chosen for this study are two ionic lamellar solids, the cationic clay montmorillonite and the anionic clay hydrotalcite. The smectite clay, montmorillonite, is a 2:1 layered silicate; two tetrahedral sheets containing $\mathrm{Si}^{4+}$ sandwiching a sheet of octahedrally coordinated $\mathrm{Al}^{3+}$ ions. Part of the $\mathrm{Al}^{3+}$ ions in the octahedra are substituted by $\mathrm{Mg}^{2+}$ and the charge deficit of the negatively charged layers compensated by interlamellar cations that are usually hydrated. The anionic clays or layered double hydroxides (LDH) are derived from the brucite $\left(\mathrm{Mg}(\mathrm{OH})_{2}\right)$ structure by the isomorphous substitution of $\mathrm{M}^{2+}$ ions by $\mathrm{M}^{3+}$ ions. The $\mathrm{LDH}$ layers are positively charged and charge neutrality is realized by the presence of interlamellar anions. When $\mathrm{M}^{3+}$ is $\mathrm{Al}^{3+}$ the mineral hydrotalcite is obtained. It may be argued, that if the charges on the cationic montomorillonite and anionic hydrotalcite are tuned, by suitable substitutions, to be identical then their exfoliated sheets could, in principle, self-asseble in an alternating fashion to give an electrically neutral crystalline hybrid. Such a scenario is, however, most unlikely for although the total charge on these electrically insulating sheets can be made identical, there is no way to control the distribution of the positive charges on the montmorillonite sheets or the negative charges on the hydrotalcite sheets as the substitutions that create these charge on the layers are random. Here we adopt a different approach to circumvent this problem. We first prepare neutral exfoliated nanosheets of montmorillonite and hydrotacite separately and show that they self-assemble as a periodically alternating layered structure.

Recently a simple approach to exfoliate layered double hydroxide solids to their ultimate constituent, intact single sheets of nanometer thickness and micron size in non-polar solvents like toluene had been outlined ${ }^{34}$. The method involved intercalation of an anionic surfactant to form a hydrophobic anchored surfactant bilayer in the interlamellar space of the LDH. Delamination was effected by simply stirring the surfactant intercalated layered solid in the solvent. The method was rapid but at the same time gentle enough to produce exfoliated nanosheets of regular morphology. A distinctive feature of the procedure was that the exfoliated nanosheets are electrically neutral as the ionic surfactant chains remain tethered to the inorganic sheets. It was shown that delamination occurs because of the inclusion of nonpolar solvent molecules in the interlayer space. These solvent molecules weaken the attractive dispersive interactions between the chains tethered to opposing inorganic layers thereby facilitating separation of the layers. The method is general, and should, in principle, be applicable to other layered solids that have been intercalated with appropriate long chain surfactants that render their interlamellar space hydrophobic.

\section{Results}

The anionic clay $\mathrm{Mg}_{0.66} \mathrm{Al}_{0.33}(\mathrm{OH})_{2}\left(\mathrm{NO}_{3}\right)_{0.33}(\mathrm{Mg}-\mathrm{Al} \mathrm{LDH})$ with $\mathrm{NO}_{3}{ }^{-}$as the interlamellar anion was prepared by reported procedures $^{35}$. Na-montmorillonite (Na-MMT) was obtained from Southern Clay Product Inc., USA (Na-Cloisite) and has the formula

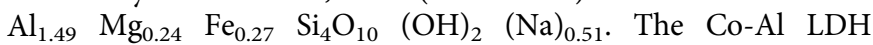
$\left(\mathrm{Co}_{0.67} \mathrm{Al}_{0.33}(\mathrm{OH})_{2}\left(\mathrm{NO}_{3}\right)_{0.33}\right)$ was also prepared to help in establishing the stoichiometry of the hybrid and to demonstrate that the procedures, described subsequently, are universal and can be applied to other anionic clays. Procedures for the intercalation of ionic surfactants in these materials as well as their characterization by powder X-ray Diffraction (XRD) are well established ${ }^{36-39}$. Intercalation occurs with an increase in the interlayer separation that depends on the chain length of the surfactant. The cationic surfactant intercalated in the smectite clay, montmorillonite, was the di-octadecyldimethyl ammonium (DODMA) ion while in the LDH it was the dodecyl sulfate (DDS) anion. The X-ray determined interlayer spacings of the intercalated MMT-DODMA and Mg-Al LDH-DDS are $3.91 \mathrm{~nm}$ and $2.81 \mathrm{~nm}$ respectively. This inter-layer spacing is characteristic of a bilayer arrangement of the intercalated surfactant chains with the ionic head group anchored to the inorganic sheets and with no interdigitation of the surfactant alkyl chains ${ }^{36,40}$. Delamination of the surfactant layered solids was effected by dispersing 10.0 to $50.0 \mathrm{mgs}$ of the solid in $100 \mathrm{ml}$ of chloroform or any other non-polar organic solvent followed by either stirring or sonication for a maximum of 10 minutes. The observed Tyndall light scattering indicating the presence of the exfoliated inorganic nanosheets dispersed in the organic solvent (Fig. 1).

Dispersions of the nanosheets with the surfactant chains anchored to the inorganic sheets were characterized by proton NMR spectroscopy. The NMR spectra of dilute solutions of the nanosheets dispersed in deuterated chloroform show well-resolved resonances of the anchored surfactant chains (Fig. 1). The spectrum of the surfactant along with the assignment of the resonances is also shown. For the dodecyl sulfate ions tethered to the Mg-Al LDH sheets the $\alpha$ $\mathrm{CH}_{2}, \beta-\mathrm{CH}_{2}$, the $\mathrm{CH}_{2}$-chain as well as the terminal $\omega-\mathrm{CH}_{3}$ resonances appear at the same position as that of the free Na-DDS chains in chloroform solution. The same is true for the cationic DODMA chains that are anchored to the montmorillonite sheets; most resonances appear at the same position as that of free DODMA surfactant chain (Fig. 1). A significant difference, however, between the anchored and free DODMA chains is in the position of the $\alpha-\mathrm{CH}_{2}$ and the methyl head-group resonances. For the anchored DODMA the $\alpha-\mathrm{CH}_{2}$ resonance is up-field shifted and the head-group $\mathrm{CH}_{3}$ resonance absent. This is a consequence of the proximal charge of the layers and the restricted rotational freedom of the head-group $\mathrm{CH}_{3}$ units as consequence of the anchoring of the DODMA chains to the inorganic sheets. The NMR spectra provides evidence that the schematic cartoon of the surfactant tethered delaminated inorganic sheets as depicted in Figure 1 is essentially correct. Further support that the nanosheets are neutral was provided by zeta potential measurements. The zeta potential values of Mg-Al LDH-DDS and MMTDODMA dispersions are $-2.3 \mathrm{mV}$ and $5.6 \mathrm{mV}$, respectively. The results highlight one of the main differences of the present delamination strategy as compared to most reported methods ${ }^{23,28}$ that yield nanosheets of either positive or negatively polarity, depending on the nature of the solid being delaminated. In the procedure outlined here, however, the dispersed nanosheets are electrically neutral as the ionic surfactant chains remain tethered to the layers even after exfoliation.

The morphology and size of the exfoliated nanosheets were examined by TEM, SAED and tapping mode AFM. Representative TEM images of the delaminated nanosheets are shown in Figure 2. The TEM images show two-dimensional ultra-thin sheets of micron size. A distinctive feature of the images is that the sheets are characterized by a well-defined morphology. The Mg-Al LDH, for example, shows hexagonal morphology. The selected area electron diffraction pattern of individual sheets exhibits the characteristic diffraction patterns with six-fold symmetry establishing their single crystal nature. The conservation of lateral morphology of the nanosheets is the distinctive feature of the delamination process described here. In contrast, most reported exfoliation procedures result in fractured sheets with poorly defined morphologies. The tapping mode AFM images shows two- dimensional ultra-thin sheets with lateral dimension up to $200 \mathrm{~nm}$. The height profile reveals that the sheets have a fairly flat, smooth terrace with an average thickness that corresponds to that of a single inorganic layer. For the layered double hydroxides, $\mathrm{Mg}-\mathrm{Al} \mathrm{LDH}$, the thickness of the sheets in the tapping mode AFM images are typically $0.5 \mathrm{~nm}$. The thickness of the hydrotalcite sheet is 


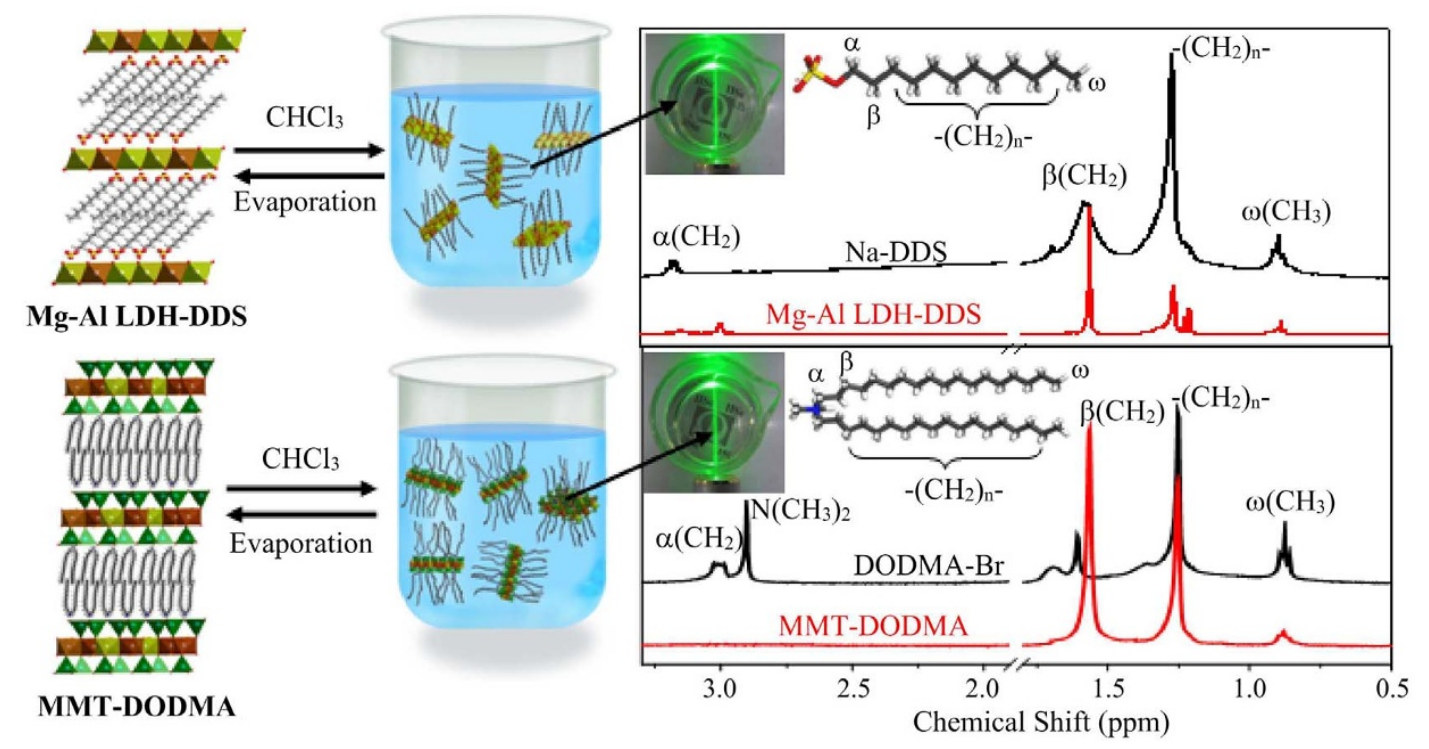

Figure 1 Schematic cartoon of the delamination of surfactant intercalated hydrotalcite and montmorillonite layered solids. The dispersions exhibit the Tyndall effect as shown in the accompanying photographs. The panel on the right shows the ${ }^{1} \mathrm{H}$ NMR of dispersions of Mg-Al LDH-DDS and MMT-DODMA in $\mathrm{CDCl}_{3}$. The assignments of the resonances are indicated. For comparison the NMR spectra of the surfactants Na-DDS and DODMA$\mathrm{Br}$ in $\mathrm{CDCl}_{3}$ are also shown.

$0.48 \mathrm{~nm}^{41}$. The softer surfactant layer is not seen in the tapping-mode AFM image of the Mg-Al LDH-DDS because of the stiff cantilever used for recording the images. The typical thickness of the MMTDODMA sheets in the AFM images are $1.02 \mathrm{~nm}$. The thickness of a montmorillonite sheet is $0.98 \mathrm{~nm}^{42}$. It may be pointed out that the observation of single sheets in the AFM images is a consequence of the fact that the delaminated sheets are electrically neutral.

We found that when the chloroform dispersions of the surfactant hydrotalcite and montmorillonite were mixed and the solvent allowed to evaporate, the X-ray diffraction pattern of the resulting solid showed additional reflections different from that of either the surfactant intercalated hydrotalcite or montmorillonite. Figure 3a shows the X-ray diffraction patterns of the resultant solid obtained on mixing different molar ratios of chloroform dispersions of $\mathrm{Mg}-\mathrm{Al}$ LDH-DDS and MMT-DODMA and allowing the solvent to evaporate. As mentioned earlier, on solvent evaporation from the single component dispersion the original solid is recovered. The pure $\mathrm{Mg}$ $\mathrm{Al}$ LDH-DDS dispersion gives a set of seven 001 Bragg reflection on solvent evaporation corresponding to an interlayer spacing of $2.81 \mathrm{~nm}$ (Fig. 3c(i)). This interlayer spacing is identical to that of the starting Mg-Al LDH-DDS (Supplementary Fig. S1) that had been shown to correspond to an anchored bilayer arrangement with the intercalated surfactant chains tilted away from the interlayer normal and adopting an all-trans conformation ${ }^{43}$. For the pure MMTDODMA dispersion a set of $1200 \mathrm{l}$ Bragg reflection are observed (Fig. 3c(ii)), on solvent evaporation, corresponding to an interlayer spacing of $3.91 \mathrm{~nm}$, identical to the starting layered solid (Supplementary Fig. S3). It may be seen, however, that on addition of montmorillonite to the $\mathrm{Mg}-\mathrm{Al} \mathrm{LDH}$ dispersion a new set of reflections (shaded peaks in Fig. 3a) are observed that do not correspond to either that of MMT-DODMA or Mg-Al LDH-DDS. At a molar ratio of $1: 1$, peaks corresponding to neither the surfactant intercalated $\mathrm{Mg}$-Al $\mathrm{LDH}$ or montmorillonite are observed and only the new set of reflections are observed. The stoichiometry of this phase, $\mathrm{Mg}_{0.39} \mathrm{Al}_{0.54} \mathrm{Fe}_{0.07} \mathrm{Si}_{1.02} \mathrm{O}_{2.50}(\mathrm{OH})_{1.50}(\mathrm{DDS})_{0.17}(\mathrm{DODMA})_{0.12}$. $0.75 \mathrm{H}_{2} \mathrm{O}$, corresponds to a $1: 1$ molar composition of $\mathrm{Mg}-\mathrm{Al} \mathrm{LDH}$ DDS and MMT-DODMA. For this composition the Bragg reflections may be indexed as $00 \mathrm{l}$ reflections corresponding to an interlayer spacing of $5.85 \mathrm{~nm}$. A plot of the $d$-spacing versus $1 / l$ is linear confirming a unique interlayer spacing (Fig. 3b). The unique interlayer spacing rules out the occurrence of a randomly interstratified layered structure and indicates a structure that is periodically ordered along the interlayer normal.

The results suggest that the $1: 1$ hybrid has an alternating $\mathrm{Mg}-\mathrm{Al}$ LDH-DDS - MMT-DODMA layered structure. We found that the $\mathrm{X}$-ray diffraction patterns generated for a structure in which hydrotalcite and montmorillonite sheets alternate in a periodic fashion with an interlayer repeat of $5.85 \mathrm{~nm}$ are similar to the experimentally recorded diffraction pattern of the $1: 1$ hybrid (Fig. 3c (iii)) (Supplementary Fig. S8). It may be noted that the intercalated surfactant chains in both Mg-Al LDH-DDS and MMT-DODMA are randomly anchored and conformationally disordered and therefore do not contribute to Bragg reflections in the experimental diffraction pattern. For the calculated diffraction patterns surfactant chains are not included in the structure and also lateral registry between alternating sheets is absent. If the anchored surfactant bilayers were to adopt a similar structure as in their parent $\mathrm{Mg}-\mathrm{Al} \mathrm{LDH}-\mathrm{DDS}$ and MMT-DODMA compounds an interlayer spacing of $6.72 \mathrm{~nm}$ may be anticipated for the $1: 1$ alternating hybrid. The fact that the spacing is $5.85 \mathrm{~nm}$ suggests that the surfactant bilayers adopt a different structure in which the DDS and DODMA chains in opposing bilayers are interdigitated. The X-ray diffraction patterns of the solid recovered after solvent evaporation from mixtures of dispersions of Co-Al LDH -DDS and MMT-DODMA show a similar behaviour (Supplementary Figure S5). At a $1: 1$ molar ratio of Co-Al LDH-DDS and MMT-DODMA the X-ray diffraction shows a set Bragg reflections with an unique interlayer spacing of $5.81 \mathrm{~nm}$; the interlayer spacing of Co-Al LDH- DDS is $2.62 \mathrm{~nm}$ (Supplementary Fig. S2) and that of MMT-DODMA is $3.91 \mathrm{~nm}$ (Supplementary Fig. S3).

The TEM images of the hybrid provide additional evidence of a layered structure that is periodically ordered along the interlayer normal. The cross-sectional TEM of the starting layered solids and the $1: 1$ hybrid are shown in Figure 4 along with an expanded Fourier filtered image. The HRTEM image of the anionic clay Mg-Al LDHDDS is shown in Figure 4a. The FFT generated diffraction pattern is shown in the inset. The absence of diffraction spots with hexagonal symmetry indicating that the cross-section of the sample is indeed in the electron beam direction. The spacing measured between the two lattice fringes, $2.6 \mathrm{~nm}$, is in good agreement with the spacing determined from XRD measurements. The cross-sectional HRTEM of the 

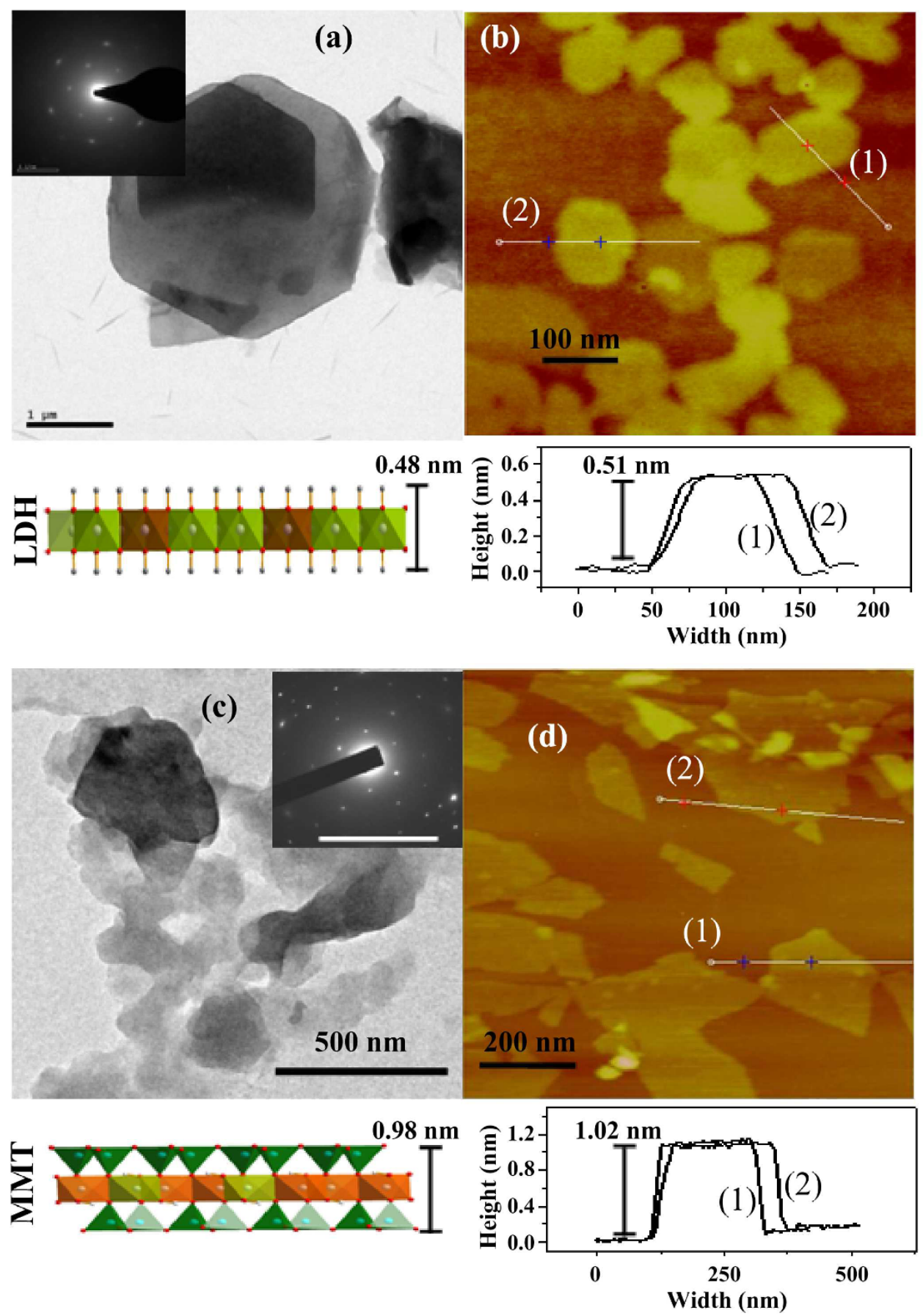

Figure 2 (a) Electron microscope images of Mg-Al LDH-DDS nanosheets. The inset shows the selected area diffraction pattern. (b) Tapping Mode AFM images of the Mg-Al LDH-DDS nanosheets. The height profiles of the sheets along the white lines marked on the images are shown in the bottom panel along with a structural model of a hydrotalcite sheet to indicate the thickness of a single layer. (c) Electron microscope and (d) Tapping Mode AFM images of the MMT-DODMA nanosheets along with a structural model of a montmorillonite sheet.

cationic clay, MMT-DODMA, is shown in Figure 4b. The spacing measured between the fringes matches with the $d$-spacing determined from the XRD pattern, $3.91 \mathrm{~nm}$. The electron diffraction pattern of the 1:1 hybrid shows diffraction rings of both $\mathrm{Mg}-\mathrm{Al}$ LDH-DDS and MMT-DODMA (Supplementary Fig. S7). What is interesting, however, is the cross-sectional TEM of the $1: 1$ hybrid (Fig. 4c) that shows a structure that is periodically ordered along the interlayer normal. The interlayer spacing measured from the TEM image of Figure $45.7 \mathrm{~nm}$ is comparable with the interlayer spacing $5.85 \mathrm{~nm}$, determined from the X-ray diffraction pattern. The distance between the spots of the FFT generated diffraction pattern (inset of Fig. 2c) is $2.9 \mathrm{~nm}$ corresponding to 002 reflection of the hybrid structure. Contrast does not permit us to distinguish between the individual hydrotalcite and montmorillonite sheets, but an Energy-dispersive X-ray spectroscopy (EDS) elemental analysis of individual layers of the corresponding $1: 1$ Co-Al LDHDDS-MMT-DODMA hybrid reveals alternation in composition (Supplementary Fig. S6) indicating that the two types of sheets alternate.

We have also attempted to address the question as to why the periodically ordered $1: 1$ alternating hybrid is obtained on solvent evaporation from a mixture of the Mg-Al LDH-DDS and MMT -DODMA 

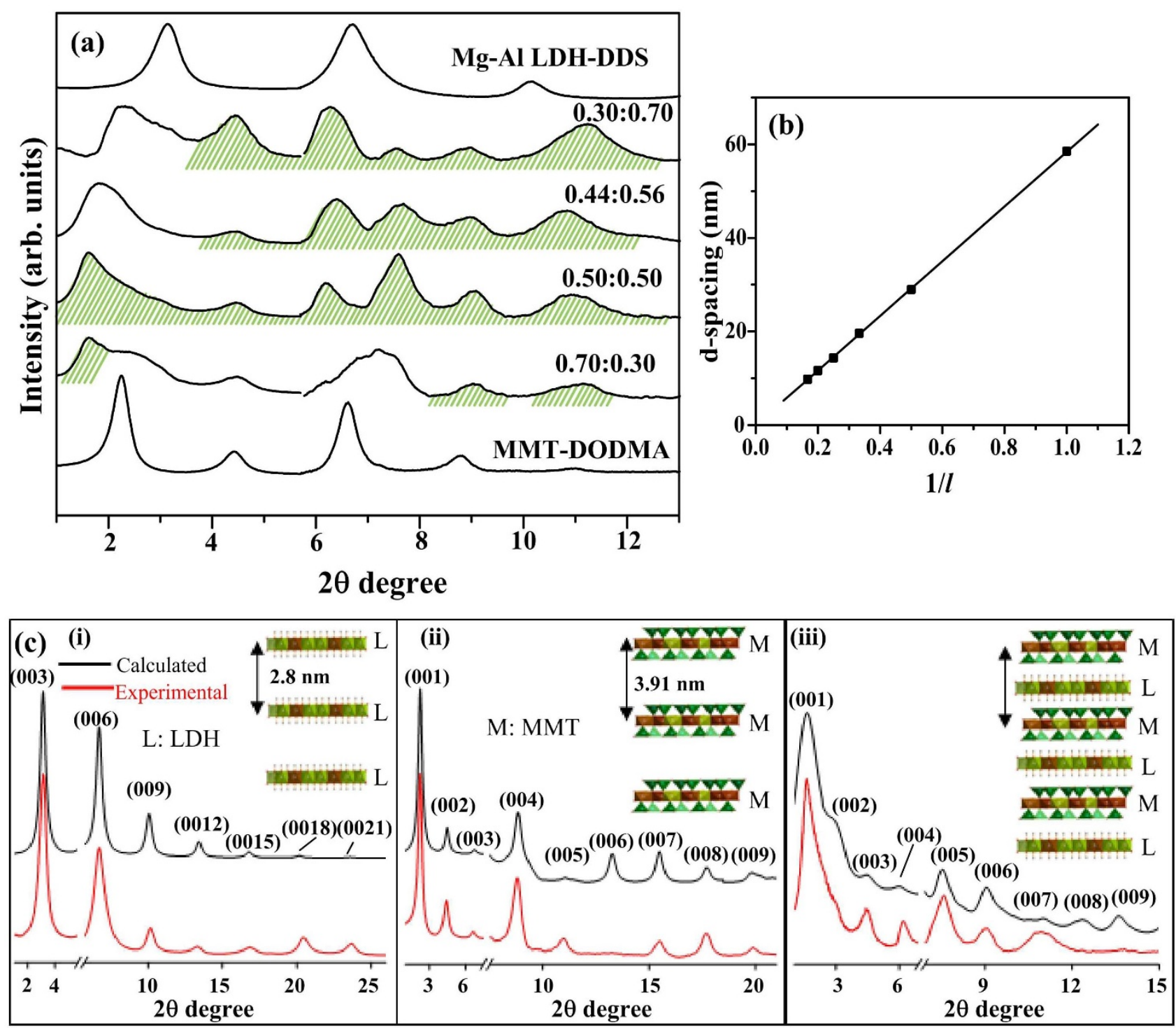

Figure 3 (a) X-ray diffraction patterns of the solid obtained on solvent evaporation from different molar ratio mixtures of dispersions of Mg-Al LDHDDS and MMT-DODMA in chloroform. The shaded features are the Bragg reflections not observed in either Mg-Al LDH-DDS or MMT-DODMA. (b) The linear variation of the $\mathrm{d}$-spacing versus $1 / l$ for the $1: 1$ hybrid. The interlayer spacing estimated from the slope is $5.85 \mathrm{~nm}$. (c) Comparison of the experimental and calculated diffraction patterns i) The experimental diffraction pattern of Mg-Al LDH-DDS along with the calculated pattern for hydrotalcite sheets stacked with an interlayer spacing of $2.81 \mathrm{~nm}$. ii) Calculated pattern for montmorillonite sheets with an interlayer spacing of $3.91 \mathrm{~nm}$ along with the experimental diffraction pattern of MMT-DODMA. iii) Calculated X-ray diffraction pattern of a periodical ordered alternating hydrotalcite montmorillonite stack with a repeat length of $5.85 \mathrm{~nm}$. The experimental X-ray diffraction pattern of the 1:1 Mg-Al LDH-DDS MMTDODMA hybrid is shown in red. The patterns were calculated using the Reflex module of the Materials Studio software package (Version 5.5.0.0, Accelrys Software Inc. (2010)).

dispersions, rather than a mixture of the individual solids. We believe that hybrid formation is a consequence of favourable electrostatic interactions between the 'tails' of the DDS anionic chains anchored to the positively charged hydrotalcite sheets and the cationic DODMA surfactant chains tethered to the negatively charged montmorillonite sheets. It may be noted that although both the Mg-Al LDH-DDS and MMT-DODMA nanosheets are electrically neutral, because the surfactant chains remain anchored even on delamination, the disposition of charges in the two nanosheets are opposite.

We believe that it is the residual charges, of opposite sign, located on the 'tails' of the DDS and DODMA alkyl chains that is responsible for hybrid formation. To test this hypothesis we took an equimolar dispersion of Mg-Al LDH-DDS and MMT-DODMA in chloroform and increased the polarity of the solvent by incremental addition of methanol. On addition of methanol the material precipitates out of the dispersion. The X-ray diffraction pattern of the precipitate shows Bragg reflections corresponding to both $\mathrm{Mg}$-Al LDH-DDS and MMT-DODMA indicating that the product of precipitation is indeed a mixture of the parent compounds (Fig. 5). These observations support the role of electrostatic forces in favouring the selfassembly of the periodically ordered alternating $1: 1$ hydrotalcitemontmorillonite hybrid.

\section{Discussion}

In summary we have shown that the surfactant intercalated hydrotalcite and montmorillonite layered solids are easily delaminated in non-polar solvents to give stable dispersions. The solids are delaminated to their ultimate constituent, single layers of atomic thickness with the ionic surfactants remaining tethered to the inorganic sheets and consequently the nanosheets are electrically neutral. We show 


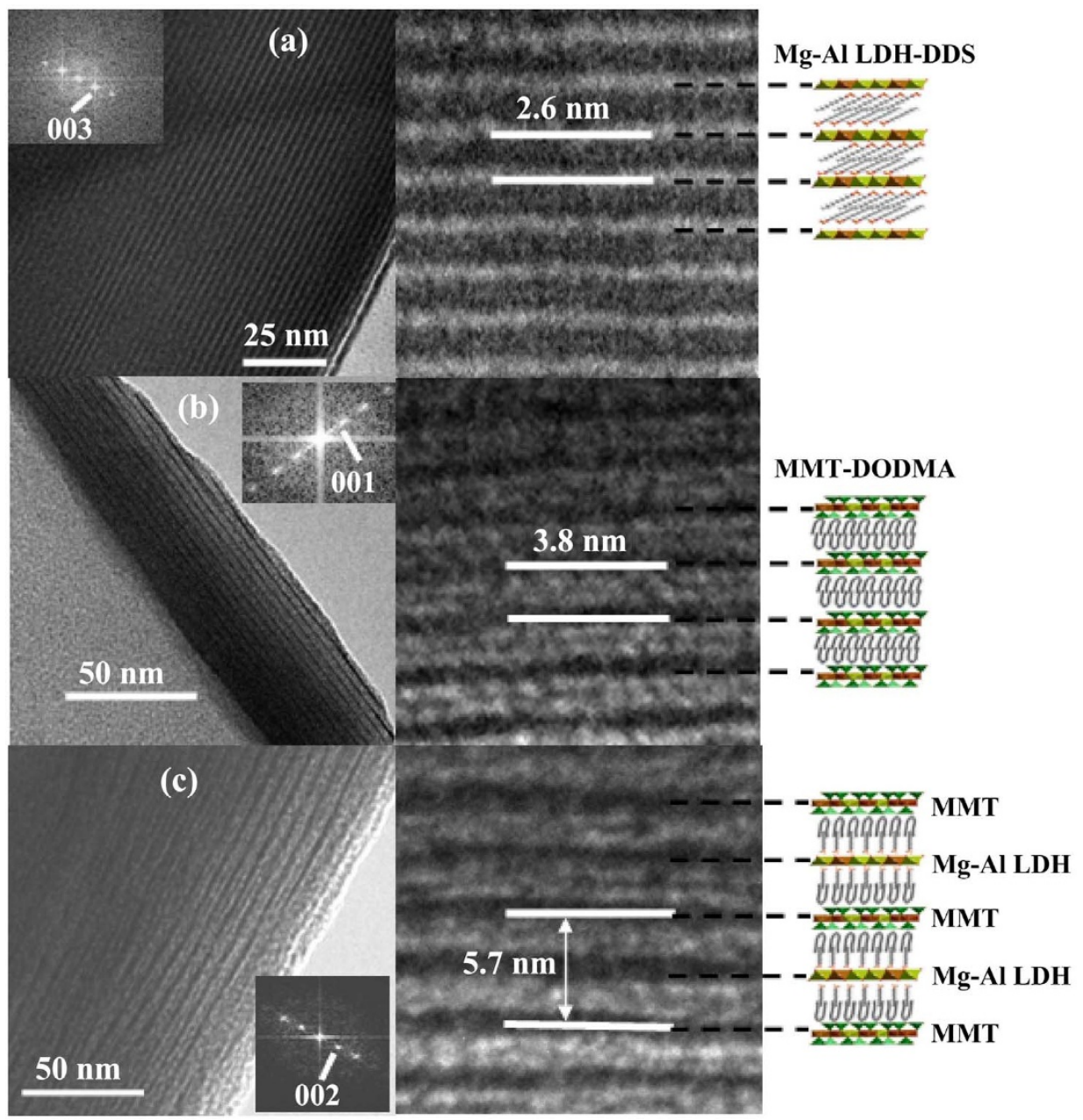

Figure $4 \mid$ Cross-sectional HRTEM of (a) Mg-Al LDH-DDS (b) MMT-DODMA and (c) the $1: 1 \mathrm{Mg}$-Al LDH-DDS MMT-DODMA hybrid. The FFT generated diffraction pattern and an enlarged view of the Fourier filtered image obtained by an inverse FFT of the diffraction pattern is shown in the panels on the right along with a structural model for each of the solids.

here that when dispersions of the two solids are mixed and the solvent allowed to evaporate a new solid is obtained in which the hydrotalcite and montmorillonite sheets alternate in a periodic fashion with a repeat length different from that of the starting surfactant intercalated hydrotalcite and montmorillonite (Fig. 6). The procedure outlined here has the advantage over thin-film techniques like the layer-bylayer method for the design of new layered hybrids as these methods require precise control and manipulation to achieve identical atomiclevel thickness of the individually deposited layers, if truly periodic superstructures are to be realized. In our method attractive forces between the neutral exfoliated nanosheets of montmorillonite and hydrotalcite ensures self-assembly of a perfectly periodically alternating layered structure. The procedure outlined here may easily be extended to other layered solids for creating new superstructures from 2D exfoliated inorganic nanosheets by self-assembly. Additionally, we believe that the significance of the present work is that it illustrates the application of the concept of crystal engineering using structural building blocks to the inorganic solid state, in much the same way as what has been achieved in the organic solid state ${ }^{1}$.

\section{Methods}

Materials. $\mathrm{Mg}\left(\mathrm{NO}_{3}\right)_{2} \cdot 6 \mathrm{H}_{2} \mathrm{O}, \mathrm{Al}\left(\mathrm{NO}_{3}\right)_{3} \cdot 9 \mathrm{H}_{2} \mathrm{O}, \mathrm{Co}\left(\mathrm{NO}_{3}\right)_{2} \cdot 6 \mathrm{H}_{2} \mathrm{O}$, ammonia solution (25\%), chloroform, methanol (SD Fine Chemicals), sodium dodecyl sulfate (NaDDS), and dioctadecyldimethylammonium bromide (DODMA-Br) (Sigma-Aldrich) were used as received without further purification.

Preparation of Mg-Al LDH-DDS. Nitrate ion intercalated Mg-Al LDH [Mg-Al LDH- $\mathrm{NO}_{3}$ ], was used as the starting material for the preparation of the surfactant

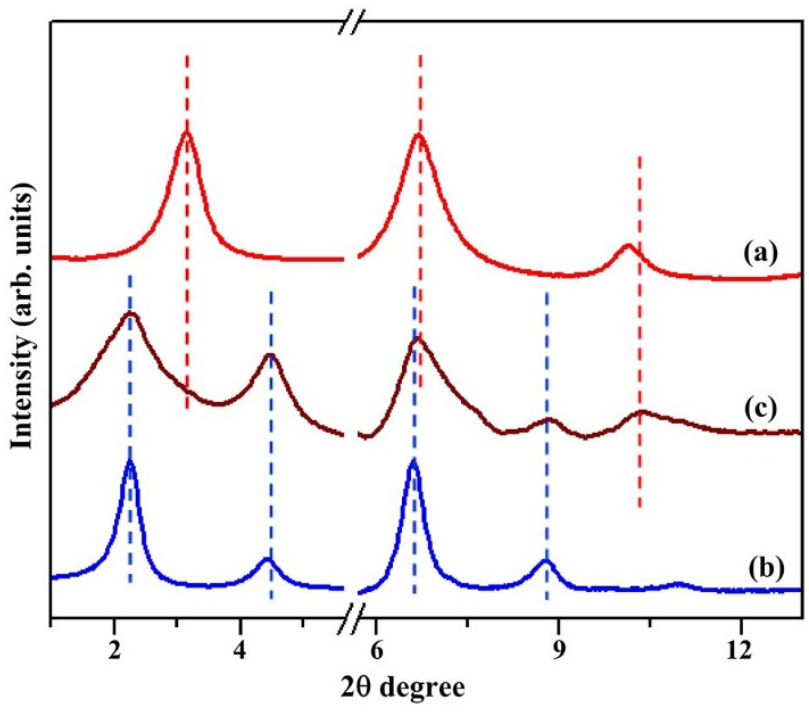

Figure $5 \mid \mathrm{X}$-ray diffraction patterns of the solid on precipitation from dispersions of (a) Mg-Al LDH-DDS, (b) MMT-DODMA and (c) $1: 1 \mathrm{Mg}$ Al LDH-DDS: MMT-DODMA in chloroform on increasing the polarity of the medium by addition of methanol. 


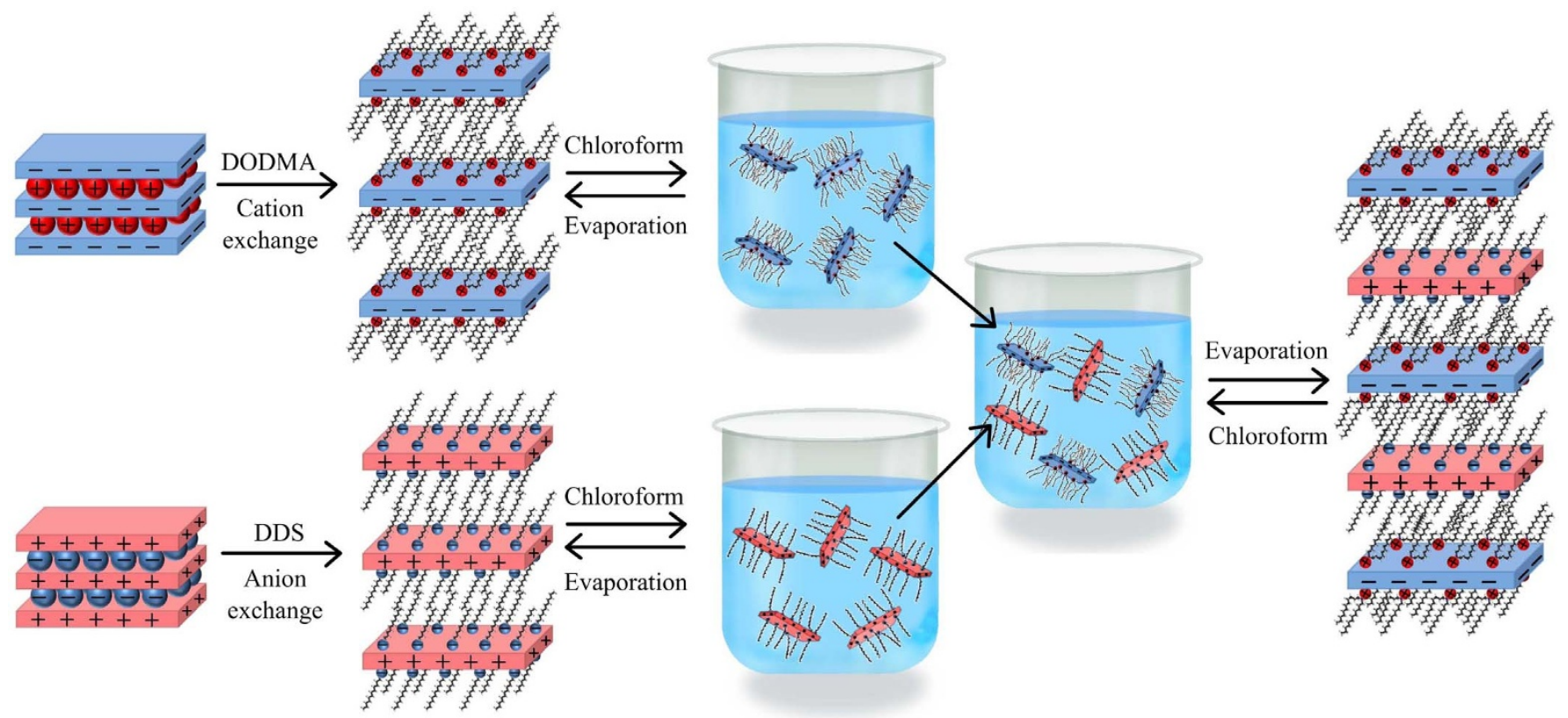

Figure 6 Shematic illustration of the formation of layered hybrids with periodically alternating positive and negatively charged inorganic sheets. The first step is the ion-exchange intercalation of long-chain ionic surfactants within the galleries of the layered solid. The ionic charge of the surfactant compliments the charge of the inorganic. Exfoliation in a non-polar solvent gives stable dispersions of neutral nanosheets that consist of the charged inorganic sheet with the ionic surfactant chains remaining anchored to the layers. Dispersions of the neutral nanosheets of the positive charged and negative charged inorganic sheets are mixed and on solvent evaporation a periodically alternating layered hybrid is obtained. In the present study the negatively charged inorganic is monmorillonite and the positively charged layers hydrotalcite.

intercalated $\mathrm{Mg}$ - $\mathrm{Al} \mathrm{LDH}-\mathrm{DDS} . \mathrm{Mg}-\mathrm{Al} \mathrm{LDH}-\mathrm{NO}_{3}$ was prepared by the coprecipitation method by drop wise addition of $100 \mathrm{~mL}$ of aqueous $\mathrm{Mg}\left(\mathrm{NO}_{3}\right)_{2}$ and $\mathrm{Al}\left(\mathrm{NO}_{3}\right)_{3}($ mole ratio of $\mathrm{Mg} / \mathrm{Al}=2)$ into aqueous ammonia solution at a constant $\mathrm{pH}$ of 8 , under $\mathrm{N}_{2}$ atmosphere $\mathrm{a}^{35}$. The resulting white precipitate was aged for $24 \mathrm{~h}$ prior to washing with decarbonated water. The anionic surfactant dodecyl sulfate (DDS) was introduced within the galleries of $\mathrm{Mg}-\mathrm{Al} \mathrm{LDH}$ by ion-exchanging the $\mathrm{NO}_{3}{ }^{-}$ions in $\mathrm{Mg}-\mathrm{Al} \mathrm{LDH}-\mathrm{NO}_{3}$ with dodecyl sulfate anions. The ion exchange reaction was carried out by stirring one equivalent of $\mathrm{Mg}-\mathrm{Al} \mathrm{LDH}-\mathrm{NO}_{3}$ with 3 equivalents of sodium dodecyl sulfate in water for $48 \mathrm{~h}$ at $70^{\circ} \mathrm{C}^{36}$. The ion exchanged $\mathrm{Mg}$-Al LDH-DDS, was filtered and washed with hot water to remove excess DDS. The formation of $\mathrm{Mg}-\mathrm{Al}$ LDH-DDS was confirmed by X-ray diffraction and Fourier transform infrared (FTIR) spectroscopy. The FTIR spectra showed absence of the characteristic $\mathrm{NO}_{3}$ band at $1384 \mathrm{~cm}^{-1}$ in the surfactant intercalated sample and the presence of new bands due to intercalated DDS ions (Supplementary Fig. S1a). The XRD patterns showed the complete absence of $00 \mathrm{l}$ reflections corresponding to $\mathrm{Mg}-\mathrm{Al} \mathrm{LDH}-\mathrm{NO}_{3}$ and the presence of new $00 \mathrm{l}$ reflections of Mg-Al LDH-DDS with a lattice spacing expansion from $0.88 \mathrm{~nm}$ to $2.81 \mathrm{~nm}$ (Supplementary Fig. S1b). The established composition of the Mg-Al LDH-DDS, $\mathrm{Mg}_{0.66} \mathrm{Al}_{0.33}(\mathrm{OH})_{2}(\mathrm{DDS})_{0.34} \cdot 0.89 \mathrm{H}_{2} \mathrm{O}$, was derived by combining the results of ICP-OES, TGA and elemental (C H N) analysis. The ratio of $\mathrm{Mg} / \mathrm{Al}$ was estimated form ICP-OES analysis by dissolving $\mathrm{Mg}-\mathrm{Al} \mathrm{LDH}-$ DDS in $\mathrm{HNO}_{3}$. The surfactant concentration and water content were determined from elemental analysis and TGA respectively.

The DDS surfactant intercalated Co-Al LDH-DDS was prepared and characterized by similar procedures (Supplementary Fig. S2a \& S2b). The stoichiometry of Co-Al LDH DDS is $\mathrm{Co}_{0.67} \mathrm{Al}_{0.33}(\mathrm{OH})_{2}(\mathrm{DDS})_{0.331} \cdot 0.66 \mathrm{H}_{2} \mathrm{O}$.

Preparation of Montmorillonite-DODMA. Na-montmorillonite (Na-MMT) was obtained from Southern Clay Product Inc., USA (Na-Cloisite) and has the formula $\mathrm{Al}_{1.49} \mathrm{Mg}_{0.24} \mathrm{Fe}_{0.27} \mathrm{Si}_{4} \mathrm{O}_{10}(\mathrm{OH})_{2}(\mathrm{Na})_{0.51}$. Na-MMT was used as the starting material for the preparation of surfactant intercalated montmorillonite. The cationic surfactant dioctadecyldimethylammonium (DODMA) was introduced within the galleries of montmorillonite by ion-exchanging the interlamellar $\mathrm{Na}^{+}$ions with dioctadecyldimethylammonium cations. The ion exchange reaction was carried out by stirring one equivalent of MMT with 3 equivalents of dioctadecyldimethylammonium bromide in a 1:1 water/methanol mixture for 48 hours at $60^{\circ} \mathrm{C}$. The ion exchanged, MMT-DODMA, was filtered and washed with water and methanol to remove excess DODMA. The formation of MMT-DODMA was confirmed using X-ray diffraction and FTIR spectroscopy. The IR spectra showed the presence of new bands due to intercalated DODMA ions, in addition to the montmorillonite bands (Supplementary Fig. S3a). The powder XRD pattern showed the complete absence of $00 \mathrm{l}$ reflections corresponding to $\mathrm{Na}$-montmorillonite and the presence of new $00 \mathrm{l}$ reflections of MMT-DODMA with a lattice spacing expansion from $1.2 \mathrm{~nm}$ to $3.91 \mathrm{~nm}$ (Supplementary Fig. S3b). The Al, Mg, Fe and Si stoichiometry were estimated from ICP-OES analysis by dissolving MMT-DODMA in $\mathrm{HF} / \mathrm{HCl}$ mixture followed by $\mathrm{HClO}_{4}$. Water content and DODMA concentrations were obtained from TGA and elemental analysis respectively. The unit cell formula of MMT-DODMA is $\mathrm{Al}_{1.49} \mathrm{Mg}_{0.24} \mathrm{Fe}_{0.27} \mathrm{Si}_{4} \mathrm{O}_{10}(\mathrm{OH})_{2}$ (DODMA) $)_{0.52} \cdot 0.35 \mathrm{H}_{2} \mathrm{O}$.

Preparation of hydrotalcite-montmorillonite hybrid. Mg-Al LDH-DDS and MMTDODMA were sonicated in chloroform separately for 15 minutes. The concentration of hydrotalcite or montmorillonite in dispersion is $2 \mathrm{mg} / \mathrm{ml}$. The dispersions of $\mathrm{Mg}$ - $\mathrm{Al}$ LDH-DDS and MMT-DODMA were mixed and sonicated for 20 minutes. This dispersion was drop coated on a glass substrate and chloroform allowed to evaporate slowly. The composition of the resultant solid was determined by ICP-OES, TGA and elemental analysis. The composition of the hybrid that gave a unique XRD pattern is $\mathrm{Mg}_{0.39} \mathrm{Al}_{0.54} \mathrm{Fe}_{0.07} \mathrm{Si}_{1.02} \mathrm{O}_{2.55}(\mathrm{OH})_{1.53}(\mathrm{DDS})_{0.17}(\mathrm{DODMA})_{0.12} \cdot 0.75 \mathrm{H}_{2} \mathrm{O}$. This indicates that the hybrid is formed when the mole ratio of hydrotalcite to montmorillonite is $1: 1$. The infrared spectra of the $1: 1$ hybrid is included as part of the Supplementary Information (Supplementary Fig. S4). The spectra show bands due to the anchored DDS and DODMA surfactant chains.

The Co-Al LDH-DDS and MMT-DODMA hybrid was prepared and characterized by procedure outlined in Supplementary Method S2 and Supplementary Figure S5 \& Figure S6. The stoichiometry and compositions of the layered solids and hybrids are summarized in Supplementary Table S1.

Physical characterization. Powder X-ray diffraction patterns were recorded on a Bruker D8 Advance machine. X-ray diffractometer using $\mathrm{Cu} \mathrm{K} \alpha$ radiation of wavelength $1.54 \AA$. In the region $1-5^{\circ}$, a scintillation detector was used while at higher angles, a Lynxeye solid state detector was used. X-ray diffraction patterns were calculated for the inorganic layered lattice by using the Reflex module of Materials Studio (Version 5.5.0.0, Accelrys Software Inc. (2010)). Patterns were calculated for the Bragg-Brentano geometry with a Lorentz function for peak profiles and peak broadening accounted by varying crystallite size. The Mg-Al LDH structure was generated from that of hydrotalcite that has a unit cell composition $\mathrm{Mg}_{2} \mathrm{Al}(\mathrm{OH})_{6}\left(\mathrm{CO}_{3}\right)_{0.5} \cdot 0.5 \mathrm{H}_{2} \mathrm{O}$ with lattice parameters $a=b=0.304 \mathrm{~nm}, c=$ $2.281 \mathrm{~nm}, \alpha=\beta=90^{\circ}, \gamma=120^{\circ}$, and space group $R \overline{3} \mathrm{~m}$ (ICSD No. 81963) ${ }^{44}$. The carbonate ions were removed and the ' $c$ ' parameter dilated to $8.43 \mathrm{~nm}$. The montmorillonite structure was generated from a unit cell composition $\mathrm{Al}_{1.5} \mathrm{Mg}_{0.5}$ $\mathrm{Si}_{4} \mathrm{O}_{10}(\mathrm{OH})_{2} \mathrm{Na}_{0.5}$ with lattice parameters $a=0.52 \mathrm{~nm}, b=0.89 \mathrm{~nm}, c=1.013 \mathrm{~nm}$, $\beta=95.73^{\circ}$ and spacegroup $C 2 / m$ (ICSD No. 160437) ${ }^{45}$. The sodium ions were removed and the ' $c$ ' parameter dilated to $3.91 \mathrm{~nm}$. The hybrid structure was generated by placing a LDH layer midway between two montmorillonite layers separated by $5.85 \mathrm{~nm}$. In the unit cell of hybrid, the number of metal $(\mathrm{Mg}+\mathrm{Al}+\mathrm{Fe})$ ions in the octahedral layer of $2: 1$ montmorillonite and the number of metal $(\mathrm{Mg}+\mathrm{Al})$ ions in the octahedral layer of the LDH was taken to be identical. This would correspond to a 1:1 molar ratio of montmorillonite and hydrotalcite layers.

TEM Bright-field images and SAED patterns were recorded on a JEOL JEM-2100F, fitted with a bottom mounted Olympus Keen View G2 CCD camera and an Oxford 
INCA Energy EDAX attachment. Analysis of the TEM images was done using the Olympus-SIS iTEM software package. For TEM analysis, dispersions of surfactant intercalated solids in toluene were cast on a holey carbon grid. Tapping mode AFM experiments were performed using a (Digital Instruments, Santa Barbara, CA) nanoscope IVA multimode AFM equipped with a A-scanner. ${ }^{1} \mathrm{H}-\mathrm{NMR}$ spectra of the delaminated layered solids dispersed in deuterated chloroform were recorded on a Bruker Avance 400 spectrometer. Thermogravimetric Analysis (TGA) profiles were recorded using a Mettler Toledo TGA/SDTA851e thermal analyzer. For TGA measurement $\sim 5$ milligram of the sample was taken in an alumina crucible and heated at a rate of $10^{\circ} \mathrm{C} / \mathrm{min}$ in a continuous flow of $\mathrm{N}_{2}$ gas. FT-IR spectra were recorded on a Perkin-Elmer Spectrum One machine operating at $4 \mathrm{~cm}^{-1}$ resolution. ICP-OES analysis was performed by using a Perkin-Elmer 2100 DV spectrometer. Elemental analysis was performed by using a Perkin-Elmer $2400 \mathrm{CHN} / \mathrm{O}$ analyzer. Zeta potential measurements were done on Brookhaven-Zetapals instrument.

1. Desiraju, G. R., Vittal, J. J. \& Ramanan, A. Crystal Engineering. A Text Book, (World Scientific Publishing, Singapore, 2011).

2. Coleman, J. N. et al. Two-dimensional nanosheets produced by liquid exfoliation of layered materials. Science 331, 568-571 (2011).

3. Golberg, D. Nanomaterials: exfoliating the inorganics. Nature Nanotech. 6 200-201 (2011).

4. Norrish, K. The swelling of montmorillonite. Discuss. Faraday Soc. 18, 120-134 (1954).

5. Wang, Q. \& O'Hare, D. Recent advances in the synthesis and application of layered double hydroxide (LDH) nanosheets. Chem. Rev. 112, 4124-4155 (2012)

6. Novoselov, K. S. et al. Two-dimensional atomic crystals. Proc. Natl. Acad. Sci. 102, 10451-10453 (2005)

7. Pinnavaia, T. J. \& Beall, G. W. Polymer-Clay Nanocomposites, (Wiley, New York, 2000).

8. Vaia, R. A. \& Giannelis, E. P. Polymer nanocomposites: status and opportunities. MRS Bull. 26, 394-401 (2001).

9. Smith, R. J. et al. Large-scale exfoliation of inorganic layered compounds in aqueous surfactant solutions. Adv. Mater. 23, 3944-3948 (2011).

10. Ma, R. \& Sasaki, T. Nanosheets of oxides and hydroxides: ultimate 2D chargebearing functional crystallites. Adv. Mater. 22, 5082-5104 (2010).

11. Coronado, E. et al. Coexistence of superconductivity and magnetism by chemical design. Nature Chem. 2, 1031-1036 (2010).

12. Walker, G. F. Macroscopic swelling of vermiculite crystals in water. Nature 187, 312-313 (1960).

13. Zhao, B., Chen, F., Gu, X. \& Zhang, J. Organic-stabilizer-free synthesis of layered protonic titanate nanosheets. Chem. Asian J. 5, 1546-1549 (2010).

14. Shaack, R. E. \& Mallouk, T. E. Exfoliation of layered rutile and perovskite tungstates. Chem. Commun. 706-707 (2002).

15. Takagaki, A. et al. Exfoliated nanosheets as a new strong acid catalyst. J. Am. Chem. Soc. 125, 5479-5485 (2003)

16. Fukuda, K. et al. Exfoliated nanosheet crystallite of cesium tungstate with 2d pyrochlore structure: synthesis, characterization and photochromic properties. ACS Nano 2, 1689-1695 (2009).

17. Leaf, A. \& Schollhorn, R. Solvation reactions of layered ternary sulfides $\mathrm{A}_{\mathrm{x}} \mathrm{TiS}_{2}$, $\mathrm{A}_{\mathrm{x}} \mathrm{NbS}_{2}$, and $\mathrm{A}_{\mathrm{x}} \mathrm{TaS}_{2}$. Inorg. Chem. 16, 2950-2956 (1977).

18. Joensen, P., Frindt, R. F. \& Morrison, S. R. Single-layer $\mathrm{MoS}_{2}$. Mater. Res. Bull. 21 , 457-461 (1986).

19. Yang, D. \& Frindt, R. F. Li-intercalation and exfoliation of $\mathrm{WS}_{2}$. J. Phys. Chem. Solids 57, 1113-1116 (1996).

20. Kim, H., Keller, S. W. \& Mallouk, T. E. Characterization of zirconium phosphate/ polycation thin films grown by sequential adsorption reactions. Chem. Mater. 9 1414-1421 (1997).

21. Nakato, T., Furumi, Y., Terao, N. \& Okuhara, T. Reaction of layered vanadium phosphorus oxides, $\mathrm{VOPO}_{4} \cdot 2 \mathrm{H}_{2} \mathrm{O}$ and $\mathrm{VOHPO}_{4} \cdot 0.5 \mathrm{H}_{2} \mathrm{O}$, with amines and formation of exfoliative intercalation compounds. J. Mater. Chem. 10, 737-743 (2000).

22. Hibino, T. \& Jones, W. New approach to the delamination of layered double hydroxides. J. Mater. Chem 11, 1321-1323 (2001).

23. Li, L., Ma, R., Ebina, Y., Iyi, N. \& Sasaki, T. Positively charged nanosheets derived via total delamination of layered double hydroxides. Chem. Mater. 17, 4386-4391 (2005).

24. Tan, J.-C., Saines, P. J., Bithell, E. G. \& Cheetham, A. K. Hybrid nanosheets of an inorganic-organic framework material: facile synthesis, structure, and elastic properties. ACS Nano 6, 615-621 (2012).

25. Mashtalir, O. et al. Intercalation and delamination of layered carbides and carbonitrides. Nat. Commun. 4, 1716 doi: 10.1038/ncomms2664 (2013).

26. Srivastava, S. \& Kotov, N. A. Composite layer-by-layer (LBL) assembly with inorganic nanoparticles and nanowires. Acc. Chem. Res. 41, 1831-1841 (2008).
27. Ma, R. \& Sasaki, T. Synthesis of LDH nanosheets and their layer-by-layer assembly. Recent Pat. Nanotech. 6, 159-168 (2012).

28. Li, L. et al. Layer-by-layer assembly and spontaneous flocculation of oppositely charged oxide and hydroxide nanosheets into inorganic sandwich layered materials. J. Am. Chem. Soc. 129, 8000-8007 (2007).

29. Akatsuka, K. et al. Construction of highly ordered lamellar nanostructures through Langmuir-blodgett deposition of molecularly thin titania nanosheets tens of micrometers wide and their excellent dielectric properties. ACS Nano. 3 , 1097-1106 (2009).

30. Li, B.-W. et al. Engineered interfaces of artificial perovskite oxide superlattices via nanosheet deposition process. ACS Nano 11, 6673-6680 (2010).

31. Kang, H. et al. Coassembly of inorganic macromolecule of exfoliated LDH nanosheets with cellulose. J. Phys. Chem. C 113, 9157-9163 (2009).

32. Desigaux, L. et al. Self-assembly and characterization of layered double hydroxide/ DNA hybrids. Nano Lett. 6, 199-204 (2006).

33. Gunjakar, J. L., Kim, T. W., Kim, H. N., Kim, I. Y. \& Hwang, S. J. Mesoporous layer-by-layer ordered nanohybrids of layered double hydroxide and layered metal oxide: highly active visible light photocatalysts with improved chemical stability. J.Am.Chem.Soc. 133, 14998-15007 (2011).

34. Naik, V. V., Ramesh, T. N. \& Vasudevan, S. Neutral nanosheets that gel: exfoliated layered double hydroxides in toluene. J. Phys. Chem. Lett. 2, 1193-1198 (2011).

35. Olanrewaju, J., Newalkar, B. L., Mancino, C. \& Komarneni, S. Simplified synthesis of nitrate form of layered double hydroxide. Mater. Lett. 45, 307-310 (2000).

36. Naik, V. V., Chalasani, R. \& Vasudevan, S. Composition driven monolayer to bilayer transformation in a surfactant intercalated $\mathrm{Mg}$-Al layered double hydroxide. Langmuir 27, 2308-2316 (2011).

37. Ogawa, M. \& Kuroda, K. Preparation of inorganic-organic nanocomposites through intercalation of organoammonium ions into layered silicates. Bull. Chem. Soc. Jpn. 70, 2593-2618 (1997).

38. de Paiva, L. B., Morales, A. R. \& Díaz, F. R. V. Organoclays: properties, preparation and applications. Appl. Clay Sci. 42, 8-24 (2008).

39. Sun, H., Zhang, J., Li, L., Xu, J. \& Sun, D. Surface modification of natural Namontmorillonite in alkane solvents using a quaternary ammonium surfactant. Colloids and Surfaces A: Physicochem. Eng. Aspects 426, 26-32 (2013).

40. Venkataraman, N. V. \& Vasudevan, S. Characterization of alkyl chain conformation in an intercalated cationic lipid bilayer by IR spectroscopy. J. Phys. Chem. B 106, 7766-7773 (2002).

41. Meyn, M., Beneke, K. \& Lagaly, G. Anion-exchange reactions of layered double hydroxides. Inorg. Chem. 29, 5201-5207 (1990)

42. Kooli, F. Exfoliation properties of acid-activated montmorillonites and their resulting organoclays. Langmuir 25, 724-730 (2009).

43. Naik, V. V. \& Vasudevan, S. Effect of alkyl chain arrangement on conformation and dynamics in a surfactant intercalated layered double hydroxide: spectroscopic measurements and MD simulations. J. Phys. Chem. C 115, 8221-8232 (2011).

44. Bellotto, M. et al. A reexamination of hydrotalcite crystal chemistry. J. Phys. Chem. 100, 8527-8534 (1996).

45. Tsipurski, S. I. \& Drits, V. A. The distribution of octahedral cations in the $2: 1$ layers of dioctahedral smectites studied by oblique-texture electron diffraction. Clay Miner. 19, 177-193 (1984).

\section{Acknowledgments}

The authors acknowledge support of the Indian Institute of Science in setting up the Chemical Sciences Division TEM facility, and the help of Dr. T.N. Ramesh in initial stages of the work.

\section{Author contributions}

The project was conceived by S.V. and executed by R.C. with A.G. contributing to the electron microscopy. The manuscript was written by R.C. and S.V.

\section{Additional information}

Supplementary information accompanies this paper at http://www.nature.com/ scientificreports

Competing financial interests: The authors declare no competing financial interests. How to cite this article: Chalasani, R., Gupta, A. \& Vasudevan, S. Engineering New Layered Solids from Exfoliated Inorganics: a Periodically Alternating Hydrotalcite Montmorillonite Layered Hybrid. Sci. Rep. 3, 3498; DOI:10.1038/srep03498 (2013).

(i) $\Theta$ This work is licensed under a Creative Commons Attributionvisit http://creativecommons.org/licenses/by-nc-nd/3.0 